\title{
FOOTEDNESS IN FITNESS AND TECHNICAL SKILLS IN YOUNG SOCCER PLAYERS
}

original paper

( ) University School of Physical Education in Wroclaw

DOI: https://doi.org/10.5114/hm.2019.84004

\section{KRZYSZTOF LIPECKI}

Cracow University of Economics, Cracow, Poland

\begin{abstract}
Purpose. The aim of the study was to identify differences in fitness abilities and technical skills between young right-footed and left-footed soccer players.

Methods. The measurements included data collected from 111 male footballers aged 12-17 years (divided into 3 age categories: U13, U15, U17). Fitness abilities (5-m, 10-m, 30-m sprint, envelope run, standing long jump) and technical skill (dribbling, juggling, short passes, long passes) were measured.

Results. The results failed to show significant differences $(p>0.05)$ in speed, agility, or explosive strength of lower limbs between right- and left-footed soccer players in the U13, U15, and U17 categories. No significant differences between soccer players (right-footed, left-footed) were found in the dominant leg performance $(p>0.005)$, whereas for the non-dominant leg, left-footed U15 players had higher performance in juggling $(p<0.05)$ and long passes $(p<0.01)$. Regardless of age category, left-footed players were characterized by a lower range of asymmetry in all technical skills. Significant differences were observed only for dribbling skills in U13 $(p<0.05)$.

Conclusions. The type of lateral dominance (right-footedness, left-footedness) does not differentiate between young soccer players in terms of fitness abilities. Left-footed footballers are more symmetrical in technical preparation compared with the right-footed ones. With age and experience in training, a reduction in functional asymmetry in technical skills is observed between lower limbs in both right- and left-footed soccer players. Regardless of the type of lateral dominance, young players have their reserves in terms of symmetrical technical preparation.
\end{abstract}

Key words: laterality, left-footed, right-footed, non-dominant leg, functional asymmetry

\section{Introduction}

Dominance of one limb over the other is observed in everyday life, both during the simplest activities and in sport. The majority of the population are people with right-sided dominance; $20 \%$ are left-sided [1]. It is interesting that the percentage of people with leftsided dominance increases significantly among athletes who reach the champion level [2]. This allows for the presumption that they have specific properties that increase their chances of being successful [3-5].

Two arguments for left-footed athletes over the right-footed ones have occurred in the literature [6]. The first is the negative frequency-dependent selection hypothesis [7], which assumes that right-sided players are less experienced and less familiar with actions taken by the left-handed players. Furthermore, the strategic advantage of the left-handed players results from the fact that both right- and left-handed people, owing to the unused visual system (negative perceptual frequency effect hypothesis) are worse in the perception and prediction of the motor patterns employed by left-handed people [8, 9]. It should be emphasized that this effect can be compensated by training [10]. The second hypothesis underlines the beneficial innate aptitudes of left-handed athletes (innate superiority hypothesis). These are manifested by lower (compared with right-handed athletes) laterality of cerebral hemispheres in terms of motor control, which helps them develop the skills in both right and left hands [11]. Moreover, a higher number or density of axons in the corpus callosum have been

Correspondence address: Krzysztof Lipecki, Faculty of Management, Department of Tourism, Cracow University of Economics, ul. Rakowicka 27, 31-510 Kraków, Poland, e-mail: lipeckik@uek.krakow.pl

Received: November 14, 2018

Accepted for publication: March 12, 2019

Citation: Lipecki K. Footedness in fitness and technical skills in young soccer players. Hum Mov. 2019;20(4):52-58; doi: https://doi.org/10.5114/hm.2019.84004. 
demonstrated in left-handed athletes [12], thus accelerating the exchange of sensory-motor information between the cerebral hemispheres [13] and, most likely, allowing for faster and more accurate movements [14].

With an insignificant number of left-footed soccer players and their natural aptitudes in terms of movement control, such athletes are especially valuable in team sports. Direct competition offers certain strategic advantage over right-footed players, whereas the specific nature of technical and tactical actions of the team makes them especially important at specific playing positions. It is indicated that in handball, each team should have at least 2 left-handed players (right midfielder, right defender), whereas the number of leftfooted players in football should reach even $40 \%$. Left-footed players are especially desired at such positions as left centre back, left fullback, left midfielder, left or right winger [15]. Experts argue that an additional advantage of left-sided players lies in their symmetrical technical preparation that improves movement versatility and unpredictability during the game [16]. This is due to the training programs, mainly based on rightsided players, with those left-sided forced to use their right limbs more often than the right-sided players have to use their left limbs [2].

A literature review reveals that most studies on laterality in team sports athletes have analysed the upper limb. Higher effectiveness was demonstrated in left-handed volleyball players [17], handball players [18], and basketball players [19]. Relatively less data have been published on lateral differentiation of lower limb performance, with the studies that compared the level of preparation of right-footed and left-footed soccer players being very scarce $[1,20]$. On the one hand, previous studies in soccer have provided information about the lack of differences in speed or strength [21, 22], technical and tactical preparation (passes, ball receiving, dribbling) between right- and left-footed players [23], except for penalty kicks, which were more efficient in left-handed players [24]. On the other hand, studies have shown that a greater number of left-footed players in a team was correlated with higher places during the most important world events (World Cup, European Championship) [2]. Furthermore, being leftfooted improves chances of the athlete for being qualified for youth national teams [25].

With the gap in the global literature in the field of research on laterality of soccer players, the aim of the presented study was to determine differences in fitness parameters (speed, explosive strength of lower limbs, agility) and technical skills (dribbling, juggling, short passes, long passes) between right-footed and leftfooted players aged 12-17 years. In addition, the in- fluence of lateral dominance of a lower limb (rightfootedness, left-footedness) on the scope of functional asymmetry in young football players has been investigated.

\section{Material and methods}

\section{Participants}

The measurements included data collected from 111 male footballers between the age of 12 and 17 years (divided into 3 age categories: U13, U15, U17) who were members of a Polish sports academy ('Progres' Sports Academy in Cracow). The U13 and U15 footballers trained 3 times a week and those from the U17 category 4 times a week. All soccer players were voluntarily recruited. All tests were performed in gymnasia under standard conditions. Prior to testing, 20-minute warm-up sessions were conducted. The soccer players were informed of the aims of the tests.

\section{Measures}

\section{Somatic measurements}

The somatic parameters were determined for each player. Body height was measured by the use of an anthropometer. Body mass was established with Tanita BC-601 electronic scales. Anthropometric parameters of the players are presented in Table 1.

\section{Determination of leg dominance}

Leg dominance was assessed in a 2-step process. The first step involved the Hoffman method [26] with a kicking task [27]. Also, a coach assumed that the dominant lower limb was used more frequently when performing different technical elements associated with the game of soccer. Only participants who demonstrated clear dominance of one leg (left or right) in these assessments entered the next step of investigation.

\section{Evaluation of fitness abilities}

Three fitness components were evaluated:

a) Speed: 5-m sprint, 10-m sprint, and 30-m sprint. Each study participant was asked to run the distance of $30 \mathrm{~m}$ as fast as possible. With the use of the Microgate photocell system (Witty System User Manual: manual version 1.4), the running time was measured over the distance of $5 \mathrm{~m}, 10 \mathrm{~m}$, and $30 \mathrm{~m}$ with the accuracy of $0.001 \mathrm{~s}$. The start line was coincident with the line of the first photocell gate, whereas other 
K. Lipecki, Footedness in fitness and technical skills in young soccer players

Table 1. Somatic characteristics of the soccer players

\begin{tabular}{|c|c|c|c|c|c|c|}
\hline Age category & $\mathrm{D}$ & $N$ & $\% N$ & $\begin{array}{c}\text { Body height (cm) } \\
\bar{x} \pm \sigma\end{array}$ & $\begin{array}{c}\text { Body mass (kg) } \\
\qquad \bar{x} \pm \sigma\end{array}$ & $\begin{array}{c}\text { BMI }\left(\mathrm{kg} / \mathrm{m}^{2}\right) \\
\bar{x} \pm \sigma\end{array}$ \\
\hline U13 & $\begin{array}{l}\mathrm{R} \\
\mathrm{L}\end{array}$ & $\begin{array}{r}36 \\
5\end{array}$ & $\begin{array}{l}87.80 \\
12.20\end{array}$ & $\begin{array}{c}150.9 \pm 6.6 \\
146.6 \pm 4.7 \\
\text { SI }\end{array}$ & $\begin{array}{c}40.8 \pm 6.6 \\
36.7 \pm 2.8 \\
\text { SI }\end{array}$ & $\begin{array}{c}17.8 \pm 1.9 \\
17.1 \pm 1.0 \\
\text { SI }\end{array}$ \\
\hline U15 & $\begin{array}{l}\mathrm{R} \\
\mathrm{L}\end{array}$ & $\begin{array}{r}23 \\
4\end{array}$ & $\begin{array}{l}85.18 \\
14.81\end{array}$ & $\begin{array}{c}166.9 \pm 9.3 \\
169.5 \pm 12.4 \\
\text { SI }\end{array}$ & $\begin{array}{c}57.0 \pm 10.9 \\
55.0 \pm 12.5 \\
\text { SI }\end{array}$ & $\begin{array}{c}20.3 \pm 2.7 \\
18.9 \pm 1.9 \\
\text { SI }\end{array}$ \\
\hline U17 & $\begin{array}{l}\mathrm{R} \\
\mathrm{L}\end{array}$ & $\begin{array}{r}36 \\
7\end{array}$ & $\begin{array}{l}83.72 \\
16.28\end{array}$ & $\begin{array}{c}178.5 \pm 5.7 \\
175.0 \pm 4.7 \\
\text { SI }\end{array}$ & $\begin{array}{c}65.3 \pm 7.1 \\
64.4 \pm 3.50 \\
\text { SI }\end{array}$ & $\begin{array}{c}21.2 \pm 1.5 \\
21.0 \pm 0.9 \\
\text { SI }\end{array}$ \\
\hline
\end{tabular}

$\mathrm{D}$ - dominant leg, R - right, L - left, $N$ - number of participants, $\% N$ - percentage of participants,

SI - statistically insignificant differences, BMI - body mass index

gates were located at the distances of 5, 10, and $30 \mathrm{~m}$. The players performed a standing start 3 times with 3 -minute rests. Further analysis was based on the best results obtained for each distance.

b) Agility: envelope run $(5 \times 3 \mathrm{~m})$ [28]. Players ran 3 laps of the specified route. Running time was measured by the Microgate photocell system (Witty System User Manual: manual version 1.4) with the accuracy of $0.001 \mathrm{~s}$. The start line with the photocell gate was located at the distance of $2 \mathrm{~m}$ from the A point at the extension of the B-A line. The start/finish gate width was $3 \mathrm{~m}$. The players performed a standing start 2 times with 3-minute rests. Further analysis was based on the best results out of the 2 trials.

c) Explosive power of lower limbs: standing long jump [28]. Further analysis was based on the best results of 3 trials.

\section{Evaluation of technical skills}

Technical skills were evaluated with motor skills tests to diagnose the following parameters [29]:

a) Speed and accuracy of ball handling with directional changes: the test of dribbling the ball between uprights with a change of direction. The player was asked to dribble the ball on a specified route (slalom between poles) using only one leg: the dominant leg (DL) or the non-dominant leg (NDL). The subject performed 2 tests for each leg and further analysis concerned the better result for DL and NDL. The test reliability was $r=0.78(p<0.05)$ for DL and $r=0.76$ $(p<0.05)$ for NDL.

b) Accuracy of short shots (passes) performed with the central instep from the air: the test of juggling alternately with the foot and the head. The number of foot-head cycles performed by a player within $30 \mathrm{~s}$ with only one leg was determined. The better result out of the 2 tests was collected separately for DL and NDL. The test reliability was $r=0.63(p<0.05)$ for DL and $r=0.76(p<0.05)$ for NDL.

c) Accuracy and speed of short shots (passes) performed low to the ground by using the medial part of the foot: the test of shots on bench performed low to the ground with the medial part of the foot. The number of goals (points) scored by the player using the shots performed low to the ground with the medial part of the foot from the distance of $6 \mathrm{~m}$ in $90 \mathrm{~s}$ was collected. Further analysis concerned the better results from the 2 tests, separately for DL and NDL. The test reliability was $r=0.56(p<0.05)$ for DL and $r=0.51$ $(p<0.05)$ for NDL.

d) Accuracy of long shots (passes) using the internal instep from the ground: the test of 20-m internal instep shots on goal from the ground. After an approach run, the player performed 20 shots $(10$ with DL and 10 with NDL, alternately) from the ground using the internal instep to the goal. The goal $(3 \times 2 \mathrm{~m})$ was divided into 2 parts with a tape ( $1 \mathrm{~m}$ from the ground); the player scored 3 points if the ball went on target (the upper part) and 1 point when it went to the lower part. Scores were not counted if the ball bounced from the ground before reaching the goal. The result was represented by the total points scored from 10 shots, separately for DL and NDL. The test reliability was $r=0.95$ $(p<0.05)$ for DL and $r=0.88(p<0.05)$ for NDL.

\section{Statistical analysis}

Distribution was analysed in groups and subgroups with the Shapiro-Wilk test (for $n<100$ ). The basic meas- 
ures (i.e. percentage distribution, means, standard deviations, confidence intervals, and coefficients of variation) were computed. Statistical hypotheses were tested between the groups stratified by age with the use of 2-way analysis of variance (ANOVA category $\times$ DL) and Tukey's post-hoc test. The reliability of the technical tests was evaluated with the test-retest method. The results obtained during one measurement were correlated ( $r$-Pearson) with those of the other measurement after 7-14 days. All tests have a reliability factor (coefficient of absolute stability) higher than 0.50 , which is considered sufficient for a group diagnosis, and it should be equal to or higher than 0.75 for an individual diagnosis [29]. The significance level assumed was $\alpha=0.05$. For data processing, the Statistica 12 PL software for Windows, version 13.0, was applied.

\section{Ethical approval}

The research related to human use has complied with all the relevant national regulations and institutional policies, has followed the tenets of the Declaration of Helsinki, and has been approved by the authors' institutional review board or an equivalent committee.

\section{Informed consent}

Informed consent has been obtained from all individuals included in this study and their parents. Also, the study was conducted with the consent of the academy to which the participants belonged.

\section{Results}

The results failed to show significant differences $(p>0.05)$ in speed, agility, or explosive strength of lower limbs between right-footed and left-footed soccer players in the U13, U15, or U17 age groups (Table 2).

The results obtained by players in technical skill tests showed no significant differences in the level of DL performance between the right-footed and leftfooted athletes $(p>0.05)$, regardless of age category. In the case of NDL, left-footed players presented higher performance in all evaluated skills, whereas significant differences were found in the U15 category for juggling $(p<0.05)$ and long passes $(p<0.01)$ (Table 3).

Furthermore, regardless of age category, left-footed players were characterized by a lower range of asymmetry in all technical skills (dribbling, juggling, short passes, long passes), whereas significant differences were found only for dribbling in the U13 group $(p<0.05)$ (Table 4).

\section{Discussion}

The first step of the study was to determine differences in the level of fitness abilities among young soccer players with various types of lateral dominance (right-footed, left-footed). The results failed to show significant differences $(p>0.05)$ in speed, agility, or explosive strength of lower limbs between right- and left-footed players in the U13, U15, and U17 groups. The findings were consistent with the reports of other authors, who also did not find significant differences in speed [21] or explosive strength of lower limbs [21, 22] between right-footed and left-footed soccer players at various sports skill levels (U8-U18). So far, no research has compared agility between right-footed and leftfooted players; thus, the results seem to be especially valuable.

Table 2. Performance data for left- and right-footed participants

\begin{tabular}{|c|c|c|c|c|c|c|c|c|}
\hline Age category & $\mathrm{D}$ & $N$ & $\% N$ & $\begin{array}{c}\text { Running } 5 \mathrm{~m} \\
\text { (s) } \\
\bar{x} \pm \sigma\end{array}$ & $\begin{array}{c}\text { Running } 10 \mathrm{~m} \\
\text { (s) } \\
\bar{x} \pm \sigma\end{array}$ & $\begin{array}{l}\text { Running } 30 \mathrm{~m} \\
\begin{array}{c}(\mathrm{s}) \\
\bar{x} \pm \sigma\end{array}\end{array}$ & $\begin{array}{c}\text { Envelope run } \\
\text { (s) } \\
\bar{x} \pm \sigma\end{array}$ & $\begin{array}{c}\text { Standing long } \\
\text { jump(cm) } \\
\bar{x} \pm \sigma\end{array}$ \\
\hline & $\mathrm{R}$ & 36 & 87.80 & $1.28 \pm 0.07$ & $2.16 \pm 0.08$ & $5.30 \pm 0.24$ & $25.47 \pm 1.19$ & $174.9 \pm 18.3$ \\
\hline U13 & $\mathrm{L}$ & 5 & 12.20 & $\begin{array}{c}1.26 \pm 0.04 \\
\text { SI }\end{array}$ & $\begin{array}{c}2.14 \pm 0.07 \\
\text { SI }\end{array}$ & $\begin{array}{c}5.25 \pm 0.26 \\
\text { SI }\end{array}$ & $\begin{array}{c}25.14 \pm 1.29 \\
\text { SI }\end{array}$ & $\begin{array}{c}173.6 \pm 14.8 \\
\text { SI }\end{array}$ \\
\hline U15 & $\begin{array}{l}\mathrm{R} \\
\mathrm{L}\end{array}$ & $\begin{array}{r}23 \\
4\end{array}$ & $\begin{array}{l}85.18 \\
14.81\end{array}$ & $\begin{array}{c}1.20 \pm 0.08 \\
1.24 \pm 0.09 \\
\text { SI } \\
\end{array}$ & $\begin{array}{l}2.01 \pm 0.11 \\
2.04 \pm 0.13 \\
\text { SI } \\
\end{array}$ & $\begin{array}{c}4.83 \pm 0.30 \\
4.92 \pm 0.33 \\
\text { SI } \\
\end{array}$ & $\begin{array}{c}24.90 \pm 0.95 \\
25.48 \pm 1.40 \\
\text { SI }\end{array}$ & $\begin{array}{c}195.8 \pm 18.7 \\
205.3 \pm 16.9 \\
\text { SI }\end{array}$ \\
\hline U17 & $\begin{array}{l}\mathrm{R} \\
\mathrm{L}\end{array}$ & $\begin{array}{r}36 \\
7\end{array}$ & $\begin{array}{l}83.72 \\
16.28\end{array}$ & $\begin{array}{c}1.13 \pm 0.07 \\
1.16 \pm 0.06 \\
\text { SI }\end{array}$ & $\begin{array}{c}1.90 \pm 0.08 \\
1.91 \pm 0.08 \\
\text { SI }\end{array}$ & $\begin{array}{l}4.49 \pm 0.21 \\
4.50 \pm 0.19 \\
\text { SI }\end{array}$ & $\begin{array}{c}24.28 \pm 1.13 \\
24.17 \pm 1.14 \\
\text { SI }\end{array}$ & $\begin{array}{c}224.9 \pm 12.1 \\
226.0 \pm 8.7 \\
\text { SI }\end{array}$ \\
\hline
\end{tabular}

D - dominant leg, R - right, L - left, $N$ - number of participants, $\% N$ - percentage of participants,

SI - statistically insignificant differences 


\section{HUMAN MOVEMENT}

K. Lipecki, Footedness in fitness and technical skills in young soccer players

Table 3. Results of technical tests for dominant and non-dominant leg in right- and left-footed footballers

\begin{tabular}{|c|c|c|c|c|c|}
\hline Age category & $\mathrm{D}$ & $\begin{array}{l}\text { Dribbling (s) } \\
\quad \bar{x} \pm \sigma\end{array}$ & $\begin{array}{c}\text { Juggling (points) } \\
\bar{x} \pm \sigma\end{array}$ & $\begin{array}{c}\text { Short passes (points) } \\
\bar{x} \pm \sigma\end{array}$ & $\begin{array}{c}\text { Long passes (points) } \\
\bar{x} \pm \sigma\end{array}$ \\
\hline \multicolumn{6}{|l|}{ Dominant leg } \\
\hline U13 & $\begin{array}{l}\mathrm{R} \\
\mathrm{L}\end{array}$ & $\begin{array}{c}29.84 \pm 2.23 \\
30.88 \pm 1.96 \\
\text { SI }\end{array}$ & $\begin{array}{c}6.19 \pm 3.51 \\
7.60 \pm 4.83 \\
\text { SI }\end{array}$ & $\begin{array}{c}12.94 \pm 2.67 \\
11.20 \pm 3.27 \\
\text { SI }\end{array}$ & $\begin{array}{c}8.63 \pm 5.13 \\
6.60 \pm 2.88 \\
\text { SI }\end{array}$ \\
\hline U15 & $\begin{array}{l}\mathrm{R} \\
\mathrm{L}\end{array}$ & $\begin{array}{c}28.95 \pm 2.72 \\
26.90 \pm 1.93 \\
\text { SI }\end{array}$ & $\begin{array}{r}9.09 \pm 3.99 \\
11.75 \pm 4.03 \\
\text { SI }\end{array}$ & $\begin{array}{c}16.17 \pm 2.19 \\
16.00 \pm 2.31 \\
\text { SI }\end{array}$ & $\begin{array}{c}8.96 \pm 5.16 \\
11.50 \pm 3.87 \\
\text { SI }\end{array}$ \\
\hline U17 & $\begin{array}{l}\mathrm{R} \\
\mathrm{L}\end{array}$ & $\begin{array}{c}27.09 \pm 1.71 \\
26.93 \pm 1.19 \\
\text { SI } \\
\end{array}$ & $\begin{array}{c}12.41 \pm 4.69 \\
13.43 \pm 2.99 \\
\text { SI }\end{array}$ & $\begin{array}{c}15.81 \pm 3.01 \\
15.57 \pm 4.08 \\
\text { SI }\end{array}$ & $\begin{array}{c}12.39 \pm 6.11 \\
14.43 \pm 8.01 \\
\text { SI }\end{array}$ \\
\hline \multicolumn{6}{|c|}{ Non-dominant leg } \\
\hline U13 & $\begin{array}{l}\mathrm{R} \\
\mathrm{L}\end{array}$ & $\begin{array}{c}34.54 \pm 3.38 \\
32.84 \pm 1.46 \\
\text { SI } \\
\end{array}$ & $\begin{array}{c}3.36 \pm 1.93 \\
4.00 \pm 2.91 \\
\text { SI } \\
\end{array}$ & $\begin{array}{c}10.40 \pm 2.53 \\
10.60 \pm 3.44 \\
\text { SI }\end{array}$ & $\begin{array}{c}1.28 \pm 2.26 \\
1.80 \pm 1.48 \\
\text { SI } \\
\end{array}$ \\
\hline U15 & $\begin{array}{l}\mathrm{R} \\
\mathrm{L}\end{array}$ & $\begin{array}{c}31.72 \pm 3.90 \\
29.20 \pm 3.94 \\
\text { SI }\end{array}$ & $\begin{aligned} 5.56 & \pm 3.08 \\
10.25 & \pm 2.87 \\
& *\end{aligned}$ & $\begin{array}{c}12.09 \pm 4.07 \\
14.75 \pm 4.03 \\
\text { SI }\end{array}$ & $\begin{array}{c}3.56 \pm 3.75 \\
9.75 \pm 4.99 \\
* *\end{array}$ \\
\hline U17 & $\begin{array}{l}\mathrm{R} \\
\mathrm{L}\end{array}$ & $\begin{array}{c}29.26 \pm 1.93 \\
28.52 \pm 1.98 \\
\text { SI }\end{array}$ & $\begin{aligned} & 8.75 \pm 5.08 \\
& 10.43 \pm 4.50 \\
& \text { SI }\end{aligned}$ & $\begin{array}{c}13.14 \pm 3.02 \\
13.43 \pm 4.16 \\
\text { SI }\end{array}$ & $\begin{array}{r}8.67 \pm 4.82 \\
10.43 \pm 5.13 \\
\text { SI }\end{array}$ \\
\hline
\end{tabular}

$\mathrm{D}$ - dominant leg, R - right, L - left, SI - statistically insignificant differences

${ }^{*} p<0.05,{ }^{*} p<0.01$

Table 4. Differences (\%) between dominant and non-dominant leg in technical tests among right- and left-footed footballers

\begin{tabular}{|c|c|c|c|c|c|c|c|}
\hline \multirow{2}{*}{ Age category } & \multirow{2}{*}{$\mathrm{D}$} & \multirow{2}{*}{$N$} & \multirow{2}{*}{$\% N$} & \multicolumn{4}{|c|}{ Percentage (\%) differences between D and ND } \\
\hline & & & & Dribbling & Juggling & Short passes & Long passes \\
\hline \multirow{3}{*}{ U13 } & $\mathrm{R}$ & 36 & 87.80 & $15.75^{* *}$ & $45.71^{* *}$ & $19.62^{* *}$ & $85.16^{* *}$ \\
\hline & $\mathrm{L}$ & 5 & 12.20 & 6.34 SI & $47.36^{*}$ & $5.35 \mathrm{SI}$ & $72.72 \mathrm{SI}$ \\
\hline & & & & * & SI & SI & SI \\
\hline \multirow{3}{*}{ U15 } & $\mathrm{R}$ & 23 & 85.18 & $9.56^{* *}$ & $38.83^{* *}$ & $25.23^{* *}$ & $60.26 * *$ \\
\hline & $\mathrm{L}$ & 4 & 14.81 & $8.55 \mathrm{SI}$ & $12.76 \mathrm{SI}$ & $7.81 \mathrm{SI}$ & $15.21 \mathrm{SI}$ \\
\hline & & & & SI & SI & SI & SI \\
\hline \multirow{3}{*}{ U17 } & $\mathrm{R}$ & 36 & 83.72 & $8.01 * *$ & $29.49^{* *}$ & $16.88^{* *}$ & $30.02 * *$ \\
\hline & $\mathrm{L}$ & 7 & 16.28 & $5.90 \mathrm{SI}$ & $22.33^{*}$ & $13.74 \mathrm{SI}$ & $27.72 S I$ \\
\hline & & & & SI & SI & SI & SI \\
\hline
\end{tabular}

$\mathrm{D}$ - dominant leg, R - right, L - left, $N$ - number of participants, $\% N$ - percentage of participants, ND - non-dominant leg,

SI - statistically insignificant differences

${ }^{*} p<0.05,{ }^{*} p<0.001$ 
The analysis of the results obtained by athletes in technical tests revealed no significant differentiation in performance using DL between right-footed and left-footed players. This implied that left-footed players were able to perform technical skills as effectively as right-footed ones. Differences between players occurred in performance using NDL. The results revealed that in all age categories (U13, U15, U17), left-footed subjects performed better for their NDL in all skills (dribbling, juggling, short passes, long passes). However, statistically significant differences were found in the U15 category for juggling $(p<0.05)$ and long passes $(p<0.01)$.

With respect to functional asymmetry of lower limbs in young soccer players, the lowest differences between DL and NDL performance were found in dribbling with left-footed players, characterized by nearly twice lower asymmetry $(6-9 \% ; p>0.05)$ than their right-footed peers $(8-16 \% ; p<0.001)$. An even lower range of asymmetry in dribbling was recorded in right-footed (3-5\%) and left-footed (2-4\%) Polish elite players aged 15-18 years [29]. Differences in short passes between DL and NDL ranged 5-13\% $(p<0.05)$ in left-footed soccer players and $19-25 \%(p<0.001)$ in right-footed ones. The asymmetry range for juggling skills was greater: $13-47 \%(p<0.05)$ in left-footed participants and $29-45 \%(p<0.001)$ in right-footed ones. The highest differences between DL and NDL abilities were documented for long passes. In left-footed players, the range of asymmetry was $15-73 \%(p>0.05)$, whereas in the right-footed ones, the value ranged $30-85 \%(p<0.001)$.

In addition, in right-footed subjects, significant differences between DL and NDL $(p<0.001)$ were observed in all categories (U13, U15, U17) and technical skills (dribbling, juggling, short passes, long passes). In left-footed players, significant differences were reported only in juggling in U13 and U17 $(p<0.05)$, whereas in the other 3 skills (dribbling, short passes, long passes) they were statistically insignificant ( $p>$ 0.05). These findings showed that compared with right-footed players, the participants with left-footed dominance were characterized by lower asymmetry in technical skills, while more symmetrical preparation can be conducive to a higher level of achievement in the sport. It is indicated that in sports where competition between players is direct in nature, the ability to play using both legs improves the offensive potential of the players while increasing their motor versatility, creativity, and unpredictability during the game [2, $16,30]$.

With respect to asymmetry depending on age (U13, U15, U17), both right-footed and left-footed players showed greater tendencies to reduce differences be- tween DL and NDL with increasing sports skill level in most of the analysed technical skills. This is manifested by mean differences in all the tests between U13 (right-footed: $41.56 \%$, left-footed: $32.94 \%$ ) and U17 participants (right-footed: $21.10 \%$, left-footed: $17.42 \%$ ). Analogous relationships among Polish players aged 15-18 years were reported by Ljach and Witkowski [29] in a longitudinal study. Regardless of the type of lateral dominance (right-footed, left-footed) and sportsskill age, differences between the performance evaluated for the right and left legs were higher than $2 \%$ for all skills. According to experts, this means that the athletes have not reached the maximal level of their abilities yet and have substantial reserves (especially those right-footed) in terms of symmetrical technical preparation [29].

The present study has some limitations. One of them is a relatively low number of left-footed players in individual age categories. Furthermore, the results concern elite male soccer players so they should not be generalized to female athletes or athletes of different levels of sports skills.

\section{Conclusions}

The type of lateral dominance (right-footedness, left-footedness) does not differentiate between young soccer players in terms of fitness abilities (speed, agility, explosive strength of lower limbs). Left-footed players are more symmetrical in technical preparation compared with right-footed ones. With age and experience in training, a reduction in functional asymmetry in technical skills is observed between lower limbs in both right- and left-footed soccer players. Regardless of age, both right- and left-footed athletes remain to have some potential reserves concerning the symmetrical technical preparation.

\section{Disclosure statement}

The author does not have any financial interest and did not receive any financial benefit from this research.

\section{Conflict of interest}

The author states no conflict of interest.

\section{References}

1. Carey DP, Smith DT, Martin D, Smith G, Skriver J, Rutland A, et al. The bi-pedal ape: plasticity and asymmetry in footedness. Cortex. 2009;45(5):650-661; doi: 10.1016/j.cortex.2008.05.011.

2. Starosta W. Movement symmetrisation: a new method to develop motor coordination and improve move- 
K. Lipecki, Footedness in fitness and technical skills in young soccer players

ment skills in beginners and advanced players [in Polish]. WSWFiT in Bialystok Scientific Annals. 2010;6:25-31.

3. Loffing F, Hagemann N. Pushing through evolution? Incidence and fight records of left-oriented fighters in professional boxing history. Laterality. 2015;20(3): 270-286; doi: 10.1080/1357650X.2014.961471.

4. Harris LJ. In fencing, what gives left-handers the edge? Views from the present and the distant past. Laterality. 2010;15(1-2):15-55; doi:10.1080/13576500701650430.

5. Breznik K. On the gender effects of handedness in professional tennis. J Sports Sci Med. 2013;12(2):346-353.

6. Tran US, Voracek M. Footedness is associated with selfreported sporting performance and motor abilities in the general population. Front Psychol. 2016;7:1199; doi: 10.3389/fpsyg.2016.01199.

7. Faurie C, Raymond M. Handedness, homicide and negative frequency-dependent selection. Proc Biol Sci. 2005;272(1558):25-28; doi: 10.1098/rspb.2004.2926.

8. Marzoli D, Lucafò C, Pagliara A, Cappuccio R, Brancucci A, Tommasi L. Both right- and left-handers show a bias to attend others' right arm. Exp Brain Res. 2015; 233(2):415-424; doi: 10.1007/s00221-014-4124-5.

9. Loffing F, Schorer J, Hagemann N, Baker J. On the advantage of being left-handed in volleyball: further evidence of the specificity of skilled visual perception. Atten Percept Psychophys. 2012;74(2):446-453; doi: 10.3758/s13414-011-0252-1.

10. Schorer J, Loffing F, Hagemann N, Baker J. Human handedness in interactive situations: negative perceptual frequency effects can be reversed! J Sports Sci. 2012;30(5):507-513; doi: 10.1080/02640414.2012. 654811.

11. Buckingham G, Main JC, Carey DP. Asymmetries in motor attention during a cued bimanual reaching task: left and right handers compared. Cortex. 2011;47(4):432440; doi: 10.1016/j.cortex.2009.11.003.

12. Westerhausen R, Kreuder F, Dos Santos Sequeira S, Walter C, Woerner W, Wittling RA, et al. Effects of handedness and gender on macro- and microstructure of the corpus callosum and its subregions: a combined high-resolution and diffusion-tensor MRI study. Brain Res Cogn Brain Res. 2004;21(3):418-426; doi: 10.1016/ j.cogbrainres.2004.07.002.

13. Cherbuin N, Brinkman C. Hemispheric interactions are different in left-handed individuals. Neuropsychology. 2006;20(6):700-707; doi: 10.1037/0894-4105.20. 6.700 .

14. Dane S, Erzurumluoglu A. Sex and handedness differences in eye-hand visual reaction times in handball players. Int J Neurosci. 2003;113(7):923-929; doi: 10.1080/00207450390220367.

15. Kleine J. The value of left-footedness [in Dutch]. Ajax Magazine. 2007;46-51.

16. Guilherme J, Garganta J, Graça A, Seabra A. Influence of non-preferred foot technical training in reducing lower limbs functional asymmetry among young foot- ball players. J Sports Sci. 2015;33(17):1790-1798; doi: 10.1080/02640414.2015.1012100.

17. Starosta W, Poloczek A, Rynkiewicz T. Analysis of performing basic technical elements by right- and lefthanded highly advanced volleyball players [in Polish]. WSWFiT in Bialystok Scientific Annals. 2011;7:27-29.

18. Loffing F, Sölter F, Hagemann N, Strauss B. Accuracy of outcome anticipation, but not gaze behavior, differs against left- and right-handed penalties in team-handball goalkeeping. Front Psychol. 2015;6:1820; doi: 10.3389/fpsyg.2015.01820.

19. Lawler TP, Lawler FH. Left-handedness in professional basketball: prevalence, performance, and survival. Percept Mot Skills. 2011;113(3):815-824; doi: 10.2466/ 05.19.25.PMS.113.6.815-824.

20. Grouios G, Kollias N, Koidou I, Poderi A. Excess of mixed-footedness among professional soccer players. Percept Mot Skills. 2002;94(2):695-699; doi: 10.2466/ PMS.2002.94.2.695.

21. Witkowski Z, Lipecki K, Lyakh V. Association of leg bias with bipedal speed and power in developing soccer players. Percept Mot Skills. 2014;118(1):293-303; doi: 10.2466/10.25.PMS.118k12w8.

22. Ljach W, Bujas P, Gargula L. Biomechanical indicators of 'left-footed' and 'right-footed' footballers aged $15-16$ in the aspect of symmetry-asymmetry of movements [in Polish]. Med Sport. 2004;8(1):238-239.

23. Carey DP, Smith G, Smith DT, Shepherd JW, Skiver J, Ord L, et al. Footedness in world soccer: an analysis of France '98. J Sports Sci. 2001;19(11):855-864; doi: 10.1080/026404101753113804.

24. Gołomazow S, Czirwa B. Futbol. Azbuka penalty. Rossijskaja Gosudarstwiennaja. Moskwa: Akadiemija Fiziczeskoj Kultury; 1999.

25. Verbeek J, Elferink-Gemser MT, Jonker L, Huijgen BCH, Visscher C. Laterality related to the successive selection of Dutch national youth soccer players. J Sports Sci. 2017;35(22):2220-2224; doi: 10.1080/02640414.2016. 1262544.

26. Hoffman M, Schrader J, Applegate T, Koceja D. Unilateral postural control of the functionally dominant and nondominant extremities of healthy subjects. J Athl Train. 1998;33(4):319-322.

27. Parkin S, Nowicky AV, Rutherford OM, McGregor AH. Do oarsmen have asymmetries in the strength of their back and leg muscles? J Sports Sci. 2001;19(7):521526; doi: 10.1080/026404101750238971.

28. Council of Europe. Eurofit: handbook for the EUROFIT tests of physical fitness. Rome: Council of Europe; 1988.

29. Ljach W, Witkowski Z. Coordinating motor skills in football [in Polish]. Warsaw: COS; 2004.

30. Antosiak-Cyrak KZ, Wilczyński G, Rostkowska EM. Laterality of the legs in young female soccer players. Hum Mov. 2015;16(4):189-194; doi: 10.1515/humo2015-0047. 